University of Wollongong

Research Online

Faculty of Engineering and Information

Faculty of Engineering and Information

Sciences - Papers: Part A

Sciences

$1-1-2014$

A new model for the prediction of earthquake ground-motion duration in Iran

Saman Yaghmaei-Sabegh

University of Tabriz, s_yaghmaei@tabrizu.ac.ir

Zhila Shoghian

University of Tabriz

M Neaz Sheikh

University of Wollongong, msheikh@uow.edu.au

Follow this and additional works at: https://ro.uow.edu.au/eispapers

Part of the Engineering Commons, and the Science and Technology Studies Commons

Research Online is the open access institutional repository for the University of Wollongong. For further information contact the UOW Library: research-pubs@uow.edu.au 


\title{
A new model for the prediction of earthquake ground-motion duration in Iran
}

\begin{abstract}
The paper proposes a new empirical model to estimate earthquake ground-motion duration, which significantly influences the damage potential of an earthquake. The paper is concerned with significant duration parameters that are defined as the time intervals between which specified values of Arias intensity are reached. In the proposed model, significant duration parameters have been expressed as a function of moment magnitude, closest site-source distance, and site condition. The predictive model has been developed based on a database of earthquake ground-motion records in Iran, containing 286 records up to the year 2007, and a random-effect regression procedure. The result of the proposed model has been compared with that of other published models. It has been found that the proposed model can predict earthquake ground-motion duration in Iran with adequate accuracy.
\end{abstract}

\section{Keywords}

iran, model, duration, prediction, motion, ground, earthquake

Disciplines

Engineering | Science and Technology Studies

\section{Publication Details}

Yaghmaei-Sabegh, S., Shoghian, Z. \& Sheikh, M. Neaz. (2014). A new model for the prediction of earthquake ground-motion duration in Iran. Natural Hazards, 70 (1), 69-92. 
A New Model for the Prediction of Earthquake Ground-motion

\section{Duration in Iran}

\section{Saman Yaghmaei-Sabegh ${ }^{1, *}$, Zhila Shoghian ${ }^{1}$}

M. Neaz Sheikh ${ }^{2}$

\footnotetext{
${ }^{a}$ Department of Civil Engineering, University of Tabriz, Tabriz, Iran

${ }^{\mathrm{b}}$ Department of Civil, Mining and Environmental Engineering, University of Wollongong, Wollongong, Australia
}

* Corresponding author. Fax: (+98-411) 334-4287

E-mail address: s_yaghmaei@ tabrizu.ac.ir (Saman Yaghmaei-Sabegh). 


\title{
A New Model for the Prediction of Earthquake Ground Motion Duration in Iran
}

\author{
Saman Yaghmaei-Sabegh ${ }^{\mathrm{a}, *}$, Zhila Shoghian ${ }^{\mathrm{a}}$ and M. Neaz Sheikh ${ }^{\mathrm{b}}$ \\ ${ }^{a}$ Department of Civil Engineering, University of Tabriz, Tabriz, Iran \\ ${ }^{\mathrm{b}}$ Department of Civil, Mining and Environmental Engineering, University of \\ Wollongong, Wollongong, Australia
}

\begin{abstract}
The paper proposes a new empirical model to estimate earthquake ground-motion duration, which significantly influences the damage potential of an earthquake. The paper is concerned with significant duration parameters that are defined as the time intervals between which specified values of Arias intensity are reached. In the proposed model, significant duration parameters have been expressed as a function of moment magnitude, closest site-source distance, and site condition. The predictive model has been developed based on a database of earthquake ground-motion records in Iran, containing 286 records up to the year 2007, and a random effect regression procedure. The result of the proposed model has been compared with that of other published models. It has been found that the proposed model can predict earthquake ground-motion duration in Iran with adequate accuracy.
\end{abstract}

Keywords: Earthquake, ground motion, significant duration, Random effect, Iran 


\section{Introduction}

Procedures for earthquake-resistant design and seismic performance assessment of structures in major seismic design codes worldwide (e.g., IBC-2006) are typically based on peak ground motion parameters (e.g., spectral acceleration and displacement) without explicitly considering cumulative damage or degradation due to the hysteretic behavior of the structure. However, recent research investigations revealed that response of a structure in the event of an earthquake depends very strongly not only on the amplitude of the ground motion but also in some cases on the duration of the ground motion (Boomer et al. 1999 and 2009; Kempton and Stewart 2006; Reinoso and Ordaz 2001). The duration of earthquake ground motion has also been shown to have significant effects on the level of damage sustained by engineered structures during moderate to strong earthquakes (Lindt and Goh 2004a). It has been observed that studies employing damage measures related to cumulative energy usually report a positive correlation between strong-motion duration and structural damage; on the other hand, studies employing damage measures using maximum response generally report no strong correlations between duration and damage (Hancock and Bommer 2006). The apparent influence of ground-motion duration on structural damage is depended on the parameter that is used to characterize the earthquake shaking levels. However, for two earthquake ground motions of similar spectral amplitude but of different duration, the motion of longer duration would be more damaging (Boomer et al. 2009). Hence, the duration of earthquake ground motion should be considered an important parameter in addition to the maximum amplitude and frequency content for adequately characterizing the effect of earthquake ground motion on seismic damage of structures.

In order to investigate the effects of the duration of earthquake ground motion on structural responses and the associated implications in the design of earthquake-resistant structures, substantial amount of research has been carried out over the past decades (Chai et al. 1998; Iervolino et al. 2006; Lindt and Goh 2004b). To facilitate more realistic seismic structural analysis, earthquake ground-motion duration needs to be considered as an essential parameter recognizing that its effect on the damage level is dependent of the type of structure and the damage metric (Hancock and Bommer 2006). In addition, it considerably affects demand parameters such as hysteretic ductility and equivalent number of cycles (Iervolino et al. 2006) and can be used to estimate dissipated energy (Nurtug and Sucuoglu 1995), hysteretic energy (Uang and Bertero 1990), and for detailed description of damage and modeling of structural failures (Fajfar and Gaspersic 1996), as well as for generating earthquake response spectrum using random vibration theory (Reinoso et al., 1990). It is envisaged that, in the near future, the effects of earthquake ground-motion duration will be taken into account in the seismic design of new structures and the seismic assessment of existing structures.

From a geotechnical point of view, the profound effects of strong-motion duration on the behaviour of saturated soils have been acknowledged and accounted for in evaluating liquefaction potential (Youd and Idriss 2001). Also, duration of strong ground motion is essential for the built-up of pore pressure in liquefiable soils and accumulation of volumetric strain in unsaturated soils (Silver and Seed 1971). Moreover, the lateral spread 
displacement resulting from soil liquefaction has been known to be related to the duration of earthquake shakings (Rauch and Martin 2000). It also plays a significant role in the analysis of permanent displacement in soils.

Ground-motion prediction equation (GMPE), which is known as a key component for seismic hazard analysis, typically serves as an appropriate tool to achieve a better description of seismic actions required for earthquake-resistant design. Likewise, model for predicting ground-motion duration can be regarded as a fundamental step towards a robust seismic evaluation of important infrastructures. Accurate estimation of expected ground-motion duration at a given site from earthquakes of different distances and magnitudes could be important for a more reliable earthquake hazard assessment. Table 1 briefly presents some of the strong ground motion duration prediction equations developed for different seismotectonic regions in the world. Considerable differences have been observed between the ground motion prediction equations which might be due to different dataset used in the analyses reflecting the characteristics of different seismotectonic regions. Hence, their application in other regions should be subjected to significant scrutiny. In recent years, therefore, significant research efforts have been focused on the expansion of regional predictive equations or re-examination of the generality of existing well-published relationships based on the recordings of a specific region, which is the main motivation behind this study. Moreover, recently developed ground motion duration prediction equations include various source parameters such as fault style, stress drop and depth to the top of rupture that are not reported (or captured) in the available earthquake ground motion dataset in Iran. Therefore, the application of the developed ground motion prediction equations in the study area of this paper needs some gross assumptions to be made for these parameters which lead to increased uncertainty in their application.

The objective of this paper is to develop new prediction equations to estimate two common measures of significant duration which are defined as the interval between the times at which 5-95\% and 5-75\% of the Arias intensity are reached and are termed as $D_{a 5}$ 95\% and $D_{a 5-75 \%}$, respectively. Apart from the moment magnitude and closest site-source distance, the effect of local site conditions is included in the proposed models. The results of this study are also compared with the results of other published models by considering the distribution of residuals against magnitude and distance.

Significant duration has been selected in this study as a more reliable predictor, as it is relatively robust with respect to the definitions of the beginning and ending thresholds (Bommer and Martinez-Pereira 1999) and well correlated to the amount of dissipated energy. In the present work, an attempt has been made to consider the issue of regional differences in the modelling of ground-motion duration for the high-seismicity region Iran, which was frequently subjected to catastrophic earthquakes in its recorded history. The proposed model, which is the first of its kind for Iran, was constructed using a random effect regression procedure and derived based on recorded strong-motion database containing 286 records up to the year 2007. 


\section{Significant duration of earthquake ground motion}

Earthquake ground-motion duration depends on the time required to release cumulative strain energy in the rupture length of the fault as well as the transmission characteristics of seismic waves passing through from the source to the site. The major difficulty in studying the duration of strong earthquake arises as this complex phenomenon needs to be defined in a simple way. Accordingly, researchers have not reached the same definition for the earthquake ground-motion duration that is best suited for all applications and hence different definitions have been presented in the literature. The three typical definitions for the ground-motion duration are termed as the bracketed-, uniform-, and significant duration. The significant duration parameter that measured from Arias intensity (Arias 1970) has been adopted herein and is described briefly in this section. Detailed description of different definitions of earthquake ground-motion duration can be found elsewhere (Bommer et al. 2009).

Significant duration is defined as the interval between the times at which different specified values of Arias intensity are reached. The advantages of the significant duration are that it considers the characteristics of the entire accelerogram and defines a continuous time window, and it is relatively stable with respect to the definitions of beginning and end thresholds. Two generic measures of this group are used as the time intervals between 5-95\% and 5-75\% Arias Intensity $\left(D_{a 5-95 \%}\right.$ and $\left.D_{a 5-75 \%}\right)$. Trifunac and Brady (1975) defined significant duration concept for the integrals of the squares of acceleration, velocity and displacement, as the time interval between which $5 \%$ and $95 \%$ of the total integral is attained. Fig. 1 indicates the significant duration $D_{a 5-95 \%}$ and $D_{a 5-75 \%}$ for 1978 Tabas, Iran earthquake at Deyhook station.

\section{Strong motion database}

The Iranian Plateau which is characterized by active faulting has been frequently struck by catastrophic earthquakes with high death tolls (Yaghmaei-Sabegh and Lam 2010). The strong ground motion records used in this study have been collated from the Building and Housing Research Center database (www.bhrc.com) and include all important earthquakes occurred in Iran up to the year 2007. It is worth noting that because of the limitations of good quality data and also lack of information about the soil type of recording stations, the final dataset has been limited to 286 records in this research. Uncorrected strong motion data were processed to make baseline and instrumental corrections; also, high-pass Butterworth filter has been applied. Fig. 2 shows the location of important earthquakes recorded on different geological units across Iran and used in this study.

Table 2 illustrates the list of the dataset used in this study indicating wide range of magnitude 3.7-7.7 and closest site-source distance 0.6-294 $\mathrm{km}$. These data are obtained form the shallow crustal earthquakes of Iran and contain two horizontal components and one vertical component. The significant durations were calculated based on the geometric mean of the values from the two horizontal components. The distribution of the selected 
dataset with respect to moment magnitude $\left(M_{w}\right)$ and closest site-source distance has been shown in Fig. 3.

It is noted that because of limited information about source geometry for the recorded earthquakes in Iran, the epicentral distance has been adopted as a distance metric by the studies for deriving ground motion attenuation relationship in Iran (Ghodrati Amiri et al. 2007). It is known that this distance measure do not perform adequately, especially for large earthquake events. Scherbaum et al (2004) observed that closest site-source distance (Joyner-Boore distance) is always smaller than the epicentral distance. The difference between these two distance measures depends on source size, fault dip, and site orientation. It was observed that the difference is dependent primarily on the magnitude, rather than closest site-source distance. As source size, fault dip and site orientation data are not available for all the recordings, distance conversion from epicentral distance to closest site-source distance have been carried out based on the mean difference observed in Scherbaum et al. (2004).

\section{Proposed model}

This section presents a brief description of the proposed model for the prediction of ground-motion duration based on a mixed effect regression analysis. The independent variables consist of the parameters that describe moment magnitude (M), closest sitesource distance $(\mathrm{R})$ and site condition or soil type (S). Thus, the proposed equation takes the following form similar to the ground motion prediction equations (GMPEs):

$$
\log \left(D_{a}\right)=f_{1}(R)+f_{2}(M)+f_{3}(S)
$$

Where $D_{a}$ is significant duration, and $f_{1}(R), f_{2}(M)$ and $f_{3}(S)$ represent the distance, magnitude and soil type, respectively. Fig. 4 and 5 show the distribution of $D_{a 5-95 \%}$ and $D_{a 5-75 \%}$ with respect to the closest site-source distance. These scatter plots demonstrate the logarithmic dependency of duration with respect to distance $(\mathrm{R})$, consequently the distance term is defined as:

$$
f_{1}(R)=\left(a_{1}+a_{2} \times \log (R)\right)^{b_{1}}
$$

Where, $a_{1}$ and $a_{2}$ are regression parameters.

Moment magnitude has been preferred as a magnitude scale in the analysis, as it corresponds to the well-defined physical property of the source and also it is known as an improved measure to avoid saturation effects for magnitudes greater than about 6 (Ozbey et al. 2004).

The magnitude dependency term $\left(f_{2}(M)\right)$ is defined as:

$$
f_{2}(M)=a_{3} \times M^{b_{2}}
$$

The effect of different soil types in the regression analysis is simply defined as below:

$$
f_{3}(S)=a_{4} S
$$

The site classification criteria in the Iranian code of practice for seismic resistant design of building are adopted herein. The site classification criteria in Iranian Code are based on average shear wave velocity in the top $30 \mathrm{~m}$ soil layers. In the code, four different site 
classes are defined as a rock site, very dense soil and soft rock site, stiff soil site, and soft soil site (Table 3). The site classification system in the Iranian code of practice is compatible with site classification system proposed in 2003 NEHRP (BSSC, 2003) where soil sites are defined as site class $\mathrm{B}, \mathrm{C}, \mathrm{D}$ and $\mathrm{E}$. In the regression analysis of this paper, site conditions is parameterized as $S=3,2,1$ and 0 , to represent rock sites (site class $B$ ), very dense soil and soft rock (site class C), stiff soil (site class D) and soft soil (site class E), respectively.

Finally, the mathematical representation of proposed model takes the following functional form:

$$
\log \left(D_{a}\right)=\left(a_{1}+a_{2} \times \log (R)\right)^{b_{1}}+a_{3} \times M^{b_{2}}+a_{4} \times S+\eta_{i}+\varepsilon_{i j}
$$

where the inter-event term $\eta_{i}$ is the event term for the earthquake event $i$ and the intraevent term $\varepsilon_{i j}$ is residual for record $j$ in event $i$. These two error terms, are assumed to be independent and normally distributed with variance $\tau^{2}$ and $\sigma^{2}$, respectively. Accordingly, the total standard error for mixed effects is then $\sqrt{\sigma^{2}+\tau^{2}}$. The coefficients $b_{1}, b_{2}, a_{1}, a_{2}, a_{3}$ and $a_{4}$ are determined by the regression analysis based on available data. Note that in the proposed form (Equation 5) the logarithms are in base 10.

Regression analyses utilizing equation (5) are performed using mixed-effect procedure based on the maximum likelihood (ML) method. The method is composed of fixed effect which is associated with an entire population, and random effects, which is associated with individual experimental units drawn at random from a population. As a result, the correlation of data recorded for a specific seismic event has been considered by applying a random effect model. Mixed effect models provide a flexible and powerful tool for analyzing grouped data which have been employed successfully to derive the empirical ground motion attenuation relationships by different researchers (Ozbey et al. 2004; Danciu and Tselentis 2007). The advantage of the proposed mixed effect approach is that, the contributions to overall variability may be clearly separated into two types: variability between different earthquakes (inter-events) and variability among recordings of the same earthquake (intra-event). More details about the application of the mixed effects model can be found in Pinheiro and Bates (2000). Table 4 presents results of the regression analysis of the proposed. Coefficients of the regression parameters and their standard deviations for both $D_{a 5-95 \%}$ and $D_{a 5-75 \%}$ have been shown in Table 4 . It is noted that inter-event variability has been fully considered in this study. However, in earlier studies ground motion duration prediction equations have been derived using leastsquared regression analysis considering equal weight to each recording and may not well correlated with the data recorded during a given event (Trifunac and Brady 1975; Bruno and Fabrice 2000; Reinoso and Ordaz 2001). 


\section{Comparison of proposed model with pervious studies}

In this section, the proposed simple model is examined by comparing the result of this study with the result from previous studies carried out from 1975 to 2009. Special emphasis has been given for the two recently published/updated models developed in Kempton and Stewart (2006) and Bommer et al. (2009). Fig. 6 shows the predicted values of $D_{a 5-95 \%}$ for fixed distance of $R=30 \mathrm{~km}$ on a rock site as a function of magnitude. The result of other studies (Trifunac and Brady 1975; Dobry and Idriss 1978; McGuire and Barnhard 1979; Kamiyama 1984; Abrahamson and Silva 1996; Bruno and Fabrice 2000; Kempton and Stewart 2006; Bommer et al. 2009) have also been superimposed in Figure 6. It is evident from Fig. 6 that the proposed model is in very good agreement with that from Bommer et al. (2009). This model, abbreviated herein as the BSA09, has been derived from the database compiled for the NGA project (Chiou et al. 2008) and its overall behaviour is similar to that proposed in this paper. Similar agreement with Kempton and Stewart (2006) and Bruno and Fabrice (2000) have been observed for low to moderate magnitude earthquake events $(M<6)$ and strong earthquake events $(M>6)$, respectively (Fig. 6). These two models have been abbreviated in this paper as $K S O 6$ and $B F O O$, respectively. However, large differences between the results of the proposed model with that of other models (Kamiyama 1984; Trifunac and Brady 1975; Dobry and Idriss 1978) developed in 70's and 80's have been observed (Fig. 6), which might be due to lack of correlation among the data recorded during a given event in these studies. Another possible reason might be that in these studies site conditions have not extensively investigated.

Residual analyses have been undertaken to examine the validity and fitness of the proposed model. Fig. 7 and 8 show the distribution of residuals for significant durations $\left(D_{\text {Obs }}-D_{\text {Pred }}\right)$ in logarithmic units based on the predictive relationships for different magnitudes and distances. Similar calculations of the residual values have also been carried out for BSA09 and KSO6 models for comparison. The residual analyses results from $B S A 09$ and $K S O 6$ have been superimposed in Fig. 7 and 8.

The good quality of the relationship based on the proposed model can be represented by (i) the spread of residuals (representing the variability of individual data values) and (ii) biases of the mean of residuals. Importantly, comparable spread of the residual with BSA09 model is observed which re-confirms the validity of this model. Generally, lower residuals are shown for these two models compared to KSO6 model with the exception of distances less than $5 \mathrm{~km}$. However, this distance is not considered important in this study.

The residuals of the proposed prediction model and the residuals of the predictions by BSA09 and KSO6 have been shown in Fig. 7 and 8. It can be seen that the proposed model shows a lower average residual $\left(2.07 \mathrm{sec}\right.$ for $D_{a 5-95 \%}$ and $0.54 \mathrm{sec}$ for $\left.D_{a 5-75 \%}\right)$ with the shallower slope of the linear trend line compared to KSO6 model (with corresponding average values of 6.61 and $1.43 \mathrm{sec}$, respectively). The BSA09 model is considered close to the proposed model and the observed residuals are 0.96 and 0.64 for $D_{a 5-95 \%}$ and $D_{a 5-75 \%}$, respectively. 
The proposed model is able to predict significant duration of earthquake ground motion with standard deviations of $7.08 \mathrm{sec}$ and $4.51 \mathrm{sec}$ for $D_{a 5-95 \%}$ and $D_{a 5-75 \%}$, respectively, which are slightly larger than the corresponding values in BSA09 Model (6.46 and 4.42 $\mathrm{sec}$ ) and is smaller than KSO6 model values $(10.28 \mathrm{sec}$ and $5.17 \mathrm{sec})$. A possible reason for this difference is that the BSA09 model has been derived based on a large dataset incorporated many records from shallow crustal earthquakes worldwide. Moreover, they include an additional variable named depth to the top of rupture, $Z_{t o r}(\mathrm{~km})$ while it is not taken into account in the new proposed model herein because the information about aforementioned parameter in the study area is inadequate.

Further residual analyses have been carried out for different soil sites in Fig. 9 ( $S=3,2,1$ and 0 , representing rock sites, very dense soil and soft rock sites, stiff soil sites, and soft soil sites, respectively). Only BSA09 model has been compared, as KSO6 model is parameterized simply for rock and soil. It can be observed from Fig. 9 that proposed model shows similar residuals to the BSA09 model.

As a final consideration in development of the proposed model, the observed data have been compared with predicted value in Fig 10. Very good agreements have been observed with all the data within $95 \%$ confidence intervals. This signified the importance of the application of the proposed model in predicting the ground motion duration of Iranian earthquakes.

\section{Conclusions}

A simple and effective empirical model for the predicting of the significant duration of ground motions have been developed in this paper based on recorded earthquake events in Iran. The significant duration of earthquake ground motion has been expressed as a function of magnitude, distance and site soil conditions. The coefficients of the independent variables in this model are determined based on a mixed effects regression procedure that accounts for inter- and intra-event ground-motion variability. The method leads to better modeling of uncertainties that propagate through the regression analysis. The results of the proposed model are in very good agreement with the observed data and are considered appropriate for the estimation of significant ground-motion duration in active tectonic regions of Iran. The developed model is expected to be of use for a number of applications both in seismology and structural engineering. Comparisons with other predictions, which are not specifically developed considering the geological and seismo-tectonic settings in Iran, have also been made in this paper. The developed model for ground motion duration may be applied to other regions of similar tectonic settings. However, it is recommended to test the fitness of the developed model before adopting it for the design and assessment of structures in other regions. The analytical model developed in this study can be significantly improved if additional high quality data become available in near future, including adequate information on soil site conditions of the recording stations. 


\section{Acknowledgement}

The authors gratefully acknowledge the contributions by Building and Housing Research

Center (BHRC) especially in providing us the strong-motion records used in this study.

\section{References}

Abrahamson NA, Silva WJ (1996) Empirical ground motion models. Report to Brookhaven National Laboratory.

Arias A (1970) A Measure of earthquake intensity. Seismic Design for Nuclear Power Plants. MIT Press Cambridge, MA. pp. 438-489.

Bommer JJ, Martinez-Pereira A (1999) The effective duration of earthquake strong motion. J Earthquake Eng 3:127-172.

Bommer JJ, Stafford PJ, Alarcón JA (2009) Empirical equations for the prediction of the significant, bracketed, and uniform duration of earthquake ground motion. Bull Seismol Soc Am 99(6): 3217-3233.

Bommer JJ, Stafford PJ, Akkar S (2010) Current empirical ground- motion prediction equations for Europe and their application to Eurocode 8. Bull Earthquake Eng 8: 5-26.

Bruno H, Fabrice C (2000) Empirical determination of ground shaking duration due to an earthquake using strong motion accelerograms for engineering applications. In Proceedings: the $14^{\text {th }}$ World Conference on Earthquake Engineering, Beijing, China, October 12-18, Paper no 2254.

Building Seismic Safety Council, BSSC (2000) NEHRP recommended provisions for seismic regulations for new buildings and other structures. Report FEMA-450 (Provisions), Washington, DC: Federal Emergency Management Agency (FEMA), 2003.

Chai YH, Fajfar P, Romstad KM (1998) Formulation of duration-dependent inelastic seismic design spectrum. J Struct Eng 124(8): 913-921.

Chiou B, Darragh R, Gregor N, Silva W (2008) NGA project strong-motion database. Earthq Spectra 24(1): 23-44.

Danciu L, Tselentis G (2007) Engineering ground motion parameters attenuation relationship for Greece. Bull Seismol Soc Am 97(1B): 162-183.

Dobry R, Idriss IM (1978) Duration characteristic of horizontal components of strong motion earthquake records. Bull Seismol Soc Am 68:1487-1520.

Esteva L, Rosenblueth E (1964) Espectros de temblores a distancias moderadas y grandes. Bull Mexican Soc of Seismic Eng 2:1-18.

Fajfar P, Gasperic P (1996) The N2 method for the seismic damage analysis of RC buildings. Earthquake Eng Struct Dyn 25:31-46. 
Ghodrati Amiri G, Mahdavian A, Manouchehri Dana F (2007) Attenuation relationships for Iran. Journal of Earthquake Engineering 11:469-492.

Hancock J, JJ Bommer (2006) A state-of-knowledge review of the influence of strong-motion duration on structural damage. Earthq Spectra 22: 827-845.

Housner GW (1965) Measures of severity of earthquake ground shaking. U.S. National Conference on Earthquake Engineering. Ann Harbor, ML.

Iervolino I, Manfredi G, Cosenza E (2006) Ground motion duration effect on nonlinear seismic response. Earthquake Eng Struct Dyn 35: 21-38.

International Code Council (2006). International Building Code, Country Club Hill; 2006.

Iranian Code of Practice for Seismic resistant Design of Buildings (2005) No.2800, 3rd edition.

Kempton JJ, Stewart PJ (2006) Prediction equations for significant duration of earthquake ground motions consideration site and near- source effects. Earthq Spectra 22: 958-1013.

Kamiyama M (1984) Effect of subsoil conditions and other factors on the duration of earthquake ground shaking. In Proceedings: 8th World Conference on Earthquake Engineering, Sanfrancisco 2: $793-800$.

Lindt JW, Goh G (2004a) Earthquake duration effect on structural reliability. J Struct Eng 130(5): 821-826.

Lindt JW, Goh G (2004b) Effect of earthquake duration on structural reliability. Eng Struct 26:1585-1597.

McGuire RK, Barnhard TP (1979) The usefulness of ground motion duration in prediction of severity shaking. In Proceedings: 2nd National Conference on Earthquake Engineering, Statford, Calif. pp.713-722.

Nurtug A, Sucuoglu H (1995) Prediction of seismic energy dissipation in SDOF systems. Earthquake Eng Struct Dyn 24:1215-122.

Ozbey C, Sari A, Manuel L, Erdik M, Fahjan Y (2004) An empirical ground motion attenuation relationships for Northwestern Turkey ground motion using a random effect approach. Soil Dyn Earthquake Eng 24:115-125.

Pinheiro JC, Bates DM (2000) Mixed-effects models in S and S-Plus. New York: Springer.

Reinoso E, Ordaz M (2001) Duration of strong ground motion during Mexican earthquakes in terms of magnitude, distance to the rupture area and dominant site period. Earthquake Eng Struct Dyn 30:653-673.

Reinoso E, Ordaz M, Sanchez-Sesma FJ (1990) A note on the fast computation of response spectra estimates. Earthquake Eng Struct Dyn 19: 971-976.

Rauch AF, Martin JR (2000) EPOLLS model for predicting average displacements on lateral spreads. J Geotech Geoenviron Eng 126(4):360-371. 
Scherbaum F, Schmedes J, Cotton F (2004) On the Conversion of Source-to-Site Distance Measures for Extended Earthquake Source Models. Bull Seismol Soc Am 94(3): 1053-1069.

Silver ML, Seed HB (1971) Volume changes in sands due to cyclic loading. JSoil Mech and Foundation Div., ASCE 97:1171-1182.

Trifunac MD, Brady AG (1975) A study on the duration of strong Earthquake ground motion. Bull Seismol Soc Am 65(3):581-626.

Uang C, Bertero V (1990) Evaluation of seismic energy in structures. Earthquake Eng Struct Dyn 19:77-90.

Yaghmaei-Sabegh S, Lam NTK (2010) Ground motion modelling in Tehran based on the stochastic method" Soil Dynamics and Earthquake Engineering 30: 525-535.

Youd TL, Idriss IM (2001) Liquefaction resistance of soils: Summary report from the 1996 NCEER and 1998 NCEER/NSF workshops on evaluation of liquefaction resistance of soils. J Geotech Geoenviron Eng 127:297-313. 
Table 1 Summary of the prediction equations for earthquake ground motion duration available in the literature

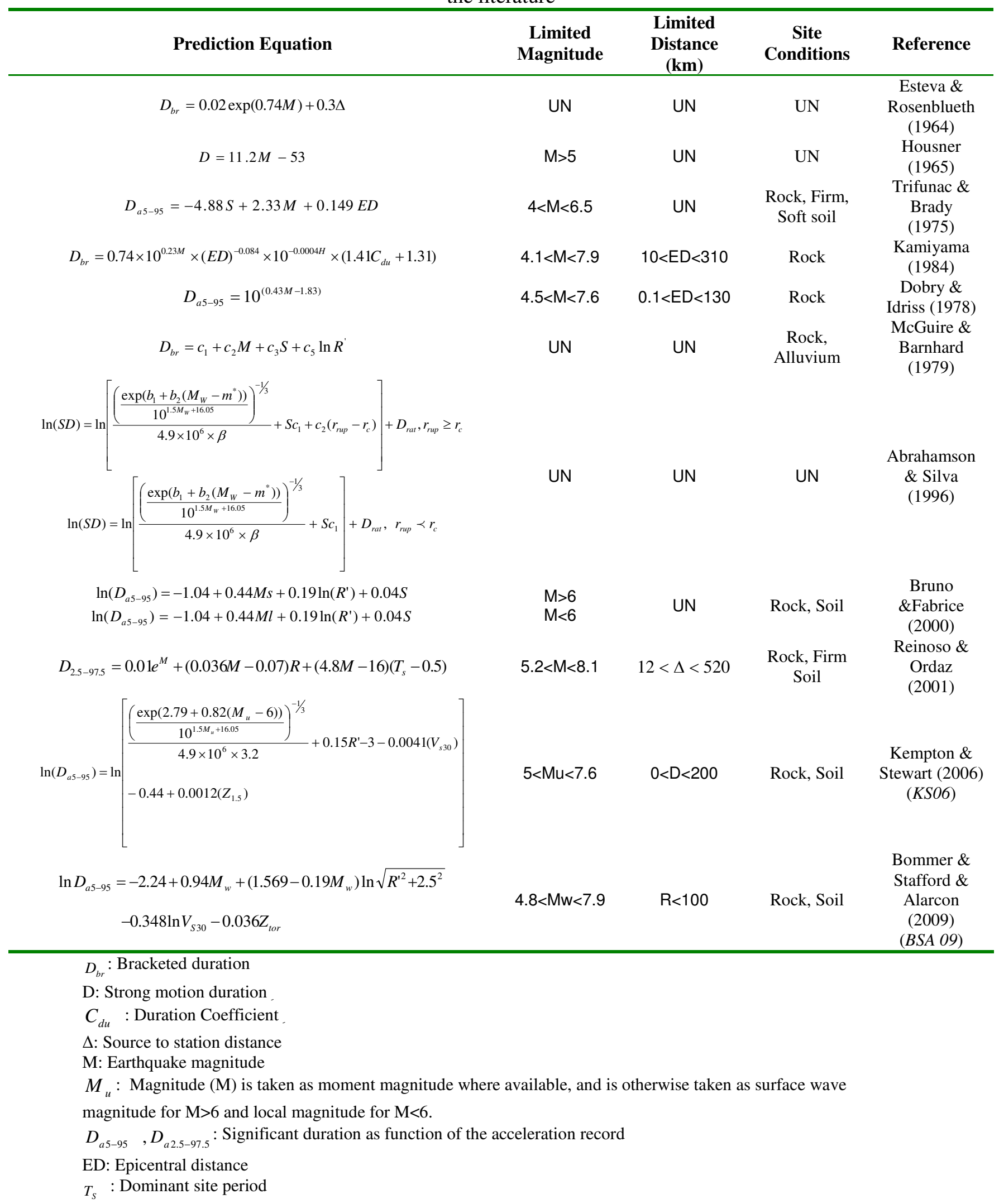


$R, r_{r u p}:$ Distance to the rupture area

Ml, Ms and Mw: Local magnitude, surface wave magnitude and moment magnitude, respectively

$\mathrm{H}$ : depth of hypocenter

$V_{S 30}:$ Shear wave velocity

$Z_{1.5}:$ Deep basin parameter

$Z_{\text {tor }}$ : Depth to the top of rupture

$R^{\prime}$ : Closest site-source distance

$S:$ Soil Type

$\beta, b_{1}, b_{2}, m^{*}, c_{1}, c_{2}, c_{3}, c_{5}, D_{\text {rat }}, r_{c}$ are regression coefficients

$\mathrm{UN}$ : Unknown 
Table 2 Summary of earthquake database in Iran: main shocks up to the year 2007

\begin{tabular}{|c|c|c|c|c|c|c|c|c|}
\hline \multirow{2}{*}{ No } & \multirow{2}{*}{$\begin{array}{c}\text { Earthquake } \\
\text { Date } \\
(y: m: d)\end{array}$} & \multirow{2}{*}{$\begin{array}{c}\text { Earthquake } \\
\text { Time } \\
\text { (h:m:s) }\end{array}$} & \multicolumn{2}{|c|}{$\begin{array}{l}\text { Geographical } \\
\text { Coordinates }\end{array}$} & \multirow{2}{*}{ Mw } & \multirow{2}{*}{$\begin{array}{l}\text { Number } \\
\text { of Record }\end{array}$} & \multirow{2}{*}{$\begin{array}{c}\text { Closest Site- } \\
\text { Source } \\
\text { Distance } \\
\text { Range }(\mathbf{k m})\end{array}$} & \multirow{2}{*}{$\begin{array}{l}\text { Number of Record } \\
\text { for Each Site Class }\end{array}$} \\
\hline & & & $\mathbf{E}$ & $\mathbf{N}$ & & & & \\
\hline 1 & 750307 & 174231 & 56.29 & 27.19 & 6.2 & 1 & 32.25 & $1 S R$ \\
\hline 2 & 750307 & 70400 & 57.07 & 27.14 & 6.2 & 1 & 69.25 & $1 \mathrm{SS}$ \\
\hline 3 & 750313 & 173313 & 50.87 & 36.81 & 4.4 & 1 & 32.8 & $1 \mathrm{SS}$ \\
\hline 4 & 751008 & 81552 & 54.41 & 28.36 & 5.4 & 1 & 13 & $1 \mathrm{HS}$ \\
\hline 5 & 751216 & 74252 & 47.92 & 39.65 & 5.4 & 1 & 51 & $1 S R$ \\
\hline 6 & 760905 & 164317 & 50.74 & 31.94 & 5.2 & 1 & 16.3 & $1 \mathrm{R}$ \\
\hline 7 & 761107 & 40050 & 59.24 & 33.33 & 6.4 & 1 & 52 & $1 \mathrm{HS}$ \\
\hline 8 & 761107 & 40050 & 59.22 & 33.73 & 6.4 & 1 & 6 & $1 \mathrm{R}$ \\
\hline 9 & 761107 & 40050 & 58.81 & 34.02 & 6.2 & 1 & 42.25 & $1 \mathrm{SR}$ \\
\hline 10 & 761124 & 122216 & 44.51 & 39.31 & 7.3 & 1 & 53 & $1 \mathrm{SR}$ \\
\hline 11 & 761109 & 175954 & 59.22 & 33.84 & 5.0 & 1 & 11 & $1 \mathrm{SR}$ \\
\hline 12 & 761109 & - & 59.17 & 33.88 & 5.3 & 1 & 7.5 & $1 \mathrm{HS}$ \\
\hline 13 & 761206 & 40604 & 44.38 & 39.06 & 3.9 & 1 & 4 & $1 \mathrm{R}$ \\
\hline 14 & 770321 & 211800 & 56.29 & 27.19 & 6.9 & 1 & 40 & $1 \mathrm{SR}$ \\
\hline 15 & 770321 & 224206 & 56.29 & 27.19 & 6.0 & 1 & 50 & $1 \mathrm{SR}$ \\
\hline 16 & 770323 & 235115 & 56.29 & 27.19 & 5.7 & 1 & 56 & $1 \mathrm{SR}$ \\
\hline 17 & 770401 & 133624 & 56.29 & 27.19 & 6.1 & 1 & 39.5 & $1 \mathrm{SR}$ \\
\hline 18 & 770406 & 133600 & 50.74 & 31.93 & 6.1 & 1 & 1.5 & $1 \mathrm{R}$ \\
\hline 19 & 770323 & 53205 & 51.39 & 29.53 & 4.6 & 1 & 7 & $1 \mathrm{R}$ \\
\hline 20 & 771021 & 145608 & 50.72 & 31.93 & 5.1 & 1 & 20.45 & $1 \mathrm{R}$ \\
\hline 21 & 771026 & 170252 & 50.72 & 31.93 & 5.4 & 1 & 63.1 & $1 \mathrm{R}$ \\
\hline 22 & 780520 & 130812 & 50.72 & 31.93 & 5.1 & 1 & 26.45 & $1 \mathrm{R}$ \\
\hline 23 & 780412 & 164824 & 50.98 & 32.1 & 5.1 & 1 & 35.45 & $1 \mathrm{SR}$ \\
\hline 24 & 780916 & 153557 & 57.44 & 33.37 & 7.3 & 1 & 22 & $1 \mathrm{R}$ \\
\hline 25 & 780916 & 163557 & 56.92 & 33.58 & 7.3 & 1 & 12 & $1 \mathrm{R}$ \\
\hline 26 & 780916 & 182547 & 57.07 & 33.79 & 4.7 & 1 & 27 & $1 \mathrm{R}$ \\
\hline 27 & 780916 & 184514 & 56.93 & 33.6 & 5.0 & 1 & 24.5 & $1 \mathrm{R}$ \\
\hline 28 & 780916 & 195021 & 56.93 & 33.6 & 5.1 & 1 & 20.5 & $1 \mathrm{R}$ \\
\hline 29 & 780917 & 73551 & 57.44 & 33.37 & 4.7 & 1 & 22 & $1 \mathrm{R}$ \\
\hline 30 & 780918 & 153507 & 56.93 & 33.6 & 5.2 & 1 & 15.4 & $1 \mathrm{R}$ \\
\hline 31 & 780919 & 11400 & 57.44 & 33.37 & 4.9 & 1 & 64 & $1 \mathrm{R}$ \\
\hline 32 & 780919 & 14919 & 56.93 & 33.6 & 5.3 & 1 & 62.5 & $1 \mathrm{R}$ \\
\hline 33 & 780829 & 141106 & 51.65 & 29.62 & 5.1 & 1 & 7.5 & 1SR \\
\hline 34 & 781609 & 193558 & 57.32 & 33.22 & 7.35 & 5 & $55.24-247$ & $1 \mathrm{SR}+4 \mathrm{HS}$ \\
\hline 35 & 790116 & 95000 & 58.18 & 34.52 & 6.8 & 1 & 137 & $1 \mathrm{R}$ \\
\hline 36 & 790116 & 95000 & 58.81 & 34.02 & 6.7 & 1 & 66 & $1 \mathrm{R}$ \\
\hline 37 & 790116 & 95000 & 58.68 & 34.35 & 6.8 & 1 & 89 & $1 \mathrm{SR}$ \\
\hline 38 & 790116 & 95000 & 60.14 & 34.57 & 6.8 & 1 & 95 & $1 \mathrm{SR}$ \\
\hline 39 & 791114 & 22118 & 59.24 & 33.33 & 6.7 & 1 & 77 & $1 \mathrm{HS}$ \\
\hline 40 & 791127 & 171033 & 59.22 & 35.27 & 7.1 & 1 & 132 & $1 \mathrm{HS}$ \\
\hline 41 & 791127 & 171033 & 59.21 & 32.87 & 7.1 & 1 & 124 & $1 \mathrm{R}$ \\
\hline 42 & 791127 & 171033 & 59.24 & 33.33 & 7.3 & 1 & 73 & $1 \mathrm{HS}$ \\
\hline 43 & 801203 & 42615 & 50.3 & 37.13 & 5.2 & 1 & 15.5 & 1SS \\
\hline 44 & 800722 & 51706 & 50.03 & 37.21 & 5.5 & 1 & 31 & $1 \mathrm{SS}$ \\
\hline 45 & 810611 & 72425 & 57.07 & 30.28 & 6.6 & 1 & 68 & $1 \mathrm{SS}$ \\
\hline 46 & 810621 & 130848 & 57.72 & 29.88 & 4.8 & 1 & 13 & $1 \mathrm{HS}$ \\
\hline 47 & 810728 & 172223 & 55.98 & 30.4 & 7.0 & 1 & 168 & $1 \mathrm{HS}$ \\
\hline 48 & 810728 & 172223 & 57.07 & 30.28 & 7.0 & 1 & 65 & $1 S S$ \\
\hline 49 & 810728 & 172223 & 57.44 & 29.59 & 7.0 & 1 & 45 & $1 \mathrm{R}$ \\
\hline 50 & 810728 & 172223 & 57.72 & 29.88 & 7.0 & 1 & 3 & $1 \mathrm{HS}$ \\
\hline 51 & 810728 & 203300 & 57.72 & 29.88 & 4.1 & 1 & 30 & $1 \mathrm{HS}$ \\
\hline 52 & 810728 & 215516 & 57.72 & 29.88 & 4.8 & 1 & 18 & $1 \mathrm{HS}$ \\
\hline 53 & 810728 & 223511 & 57.72 & 29.88 & 4.7 & 1 & 2 & $1 \mathrm{HS}$ \\
\hline 54 & 810728 & 172100 & 57.72 & 31.26 & 7.0 & 1 & 159 & $1 \mathrm{HS}$ \\
\hline 55 & 810808 & 41747 & 57.72 & 29.88 & 4.8 & 1 & 17 & $1 \mathrm{HS}$ \\
\hline 56 & 811014 & 91240 & 57.72 & 29.88 & 5.2 & 1 & 4.5 & $1 \mathrm{HS}$ \\
\hline 57 & 820225 & 235201 & 57.72 & 29.88 & 4.7 & 1 & 31 & $1 \mathrm{HS}$ \\
\hline 58 & 850819 & 124751 & 52.56 & 28.83 & 4.7 & 1 & 48 & $1 \mathrm{HS}$ \\
\hline 59 & 890315 & 192645 & 50.66 & 31.98 & 4.9 & 1 & 12.8 & $1 \mathrm{HS}$ \\
\hline 60 & 891120 & 41905 & 57.56 & 30.19 & 5.9 & 1 & 36 & $1 \mathrm{R}$ \\
\hline
\end{tabular}




\begin{tabular}{|c|c|c|c|c|c|c|c|c|}
\hline 61 & 900620 & 210011 & 49.22 & 36.09 & 7.7 & 1 & 71 & 1SS \\
\hline 62 & 900620 & 210011 & 50.28 & 37.13 & 7.4 & 1 & 75 & $1 S S$ \\
\hline 63 & 900620 & 210011 & 50.03 & 37.21 & 7.7 & 1 & 52 & $1 S S$ \\
\hline 64 & 900620 & 210011 & 50.88 & 36.81 & 7.7 & 1 & 107 & 1SS \\
\hline 65 & 900624 & 94601 & 49.39 & 36.76 & 5.2 & 1 & 14.5 & $1 S R$ \\
\hline 66 & 900620 & 210011 & 51.31 & 36.11 & 7.7 & 1 & 161 & $1 \mathrm{HS}$ \\
\hline 67 & 900620 & 210011 & 48.95 & 36.92 & 7.4 & 1 & 28 & $1 \mathrm{R}$ \\
\hline 68 & 900620 & 210011 & 48.5 & 36.66 & 7.4 & 1 & 60 & $1 \mathrm{R}$ \\
\hline 69 & 900629 & 62552 & 49.4 & 36.8 & 4.5 & 1 & 48 & $1 \mathrm{HS}$ \\
\hline 70 & 900620 & 210011 & 50.9 & 35.44 & 7.7 & 1 & 174 & 1SS \\
\hline 71 & 900620 & 210011 & 50.37 & 35.72 & 7.7 & 1 & 120 & $1 \mathrm{HS}$ \\
\hline 72 & 900706 & 193454 & 49.39 & 36.76 & 5.0 & 1 & 20.5 & 1SR \\
\hline 73 & 900821 & 34731 & 49.39 & 36.76 & 4.5 & 1 & 42 & $1 S R$ \\
\hline 74 & 900820 & 122013 & 49.4 & 36.8 & 4.8 & 1 & 41.8 & $1 \mathrm{HS}$ \\
\hline 75 & 900821 & 34731 & 49.4 & 36.8 & 5.0 & 1 & 34.8 & $1 \mathrm{HS}$ \\
\hline 76 & 901227 & 132657 & 49.4 & 36.8 & 4.8 & 1 & 51 & $1 \mathrm{HS}$ \\
\hline 77 & 900925 & 121220 & 49.4 & 36.8 & 4.8 & 1 & 36 & $1 \mathrm{SR}$ \\
\hline 78 & 900620 & 210011 & 49.4 & 36.96 & 7.7 & 12 & $39.4-245.3$ & $1 \mathrm{R}+\mathrm{SR}+4 \mathrm{HS}+6 \mathrm{SS}$ \\
\hline 79 & 910405 & 53818 & 51.39 & 29.53 & 5.2 & 1 & 43.5 & $1 \mathrm{HS}$ \\
\hline 80 & 911128 & 171958 & 49.4 & 36.8 & 5.4 & 1 & 10.5 & $1 \mathrm{HS}$ \\
\hline 81 & 911204 & 60250 & 49.4 & 36.8 & 4.3 & 1 & 35 & $1 \mathrm{HS}$ \\
\hline 82 & 920210 & 163838 & 57.56 & 30.19 & 4.7 & 1 & 7 & $1 \mathrm{R}$ \\
\hline 83 & 920908 & 3818 & 51.39 & 29.53 & 5.4 & 1 & 74.5 & $1 \mathrm{HS}$ \\
\hline 84 & 930114 & 71706 & 59.23 & 33.32 & 5.2 & 1 & 44.5 & $1 \mathrm{HS}$ \\
\hline 85 & 930502 & 175333 & 56.57 & 30.79 & 6.1 & 1 & 25.5 & $1 \mathrm{HS}$ \\
\hline 86 & 940330 & 195542 & 52.56 & 28.86 & 5.6 & 1 & 23 & $1 \mathrm{HS}$ \\
\hline 87 & 940618 & 124200 & 52.75 & 28.87 & 6.0 & 1 & 13.5 & 1SR \\
\hline 88 & 940621 & 41552 & 52.75 & 28.87 & 4.7 & 1 & 22 & $1 S R$ \\
\hline 89 & 940317 & 80616 & 52.83 & 29.1 & 4.8 & 1 & 33 & $1 \mathrm{R}$ \\
\hline 90 & 940330 & 195548 & 52.83 & 29.1 & 5.6 & 1 & 13 & $1 \mathrm{R}$ \\
\hline 91 & 940403 & 65157 & 52.83 & 29.1 & 5.4 & 1 & 30 & $1 \mathrm{R}$ \\
\hline 92 & 940618 & 124200 & 52.83 & 29.1 & 5.2 & 1 & 20 & $1 R$ \\
\hline 93 & 940620 & 90902 & 52.83 & 29.1 & 6.0 & 1 & 22.5 & $1 \mathrm{R}$ \\
\hline 94 & 940620 & 90902 & 52.56 & 28.83 & 6.0 & 1 & 11.5 & $1 \mathrm{HS}$ \\
\hline 95 & 940317 & 80616 & 52.68 & 29.2 & 4.8 & 1 & 31 & $1 \mathrm{R}$ \\
\hline 96 & 940620 & 90902 & 52.82 & 29.33 & 6.0 & 1 & 42.5 & $1 \mathrm{R}$ \\
\hline 97 & 940620 & 90902 & 52.07 & 28.87 & 6.0 & 1 & 50.5 & $1 \mathrm{SR}$ \\
\hline 98 & 940620 & 90902 & 53.22 & 28.96 & 6.0 & 1 & 57.5 & $1 S R$ \\
\hline 99 & 940317 & 80616 & 54.62 & 29.07 & 4.8 & 1 & 16 & $1 S R$ \\
\hline 100 & 940605 & 165412 & 54.62 & 29.07 & 4.8 & 1 & 65 & $1 S R$ \\
\hline 101 & 940620 & 90902 & 54.62 & 29.07 & 5.2 & 1 & 10.5 & $1 S R$ \\
\hline 102 & 940620 & 90902 & 54.62 & 29.7 & 6.0 & 1 & 8.5 & $1 \mathrm{SR}$ \\
\hline 103 & 940731 & 51539 & 48.25 & 32.68 & 5.6 & 1 & 20 & $1 S S$ \\
\hline 104 & 940731 & 52210 & 48.25 & 32.68 & 5.4 & 1 & 24 & 1SS \\
\hline 105 & 940731 & 55257 & 48.25 & 32.68 & 5.0 & 1 & 29.5 & 1SS \\
\hline 106 & 940920 & 55146 & 48.47 & 32.61 & 5.0 & 1 & 29.5 & $1 S R$ \\
\hline 107 & 940920 & 55146 & 48.31 & 32.45 & 5.2 & 1 & 38.5 & $1 \mathrm{SR}$ \\
\hline 108 & 941208 & 125438 & 52.83 & 29.1 & 5.1 & 1 & 27.5 & $1 \mathrm{R}$ \\
\hline 109 & 941208 & 125438 & 52.68 & 29.2 & 5.1 & 1 & 26.5 & $1 \mathrm{R}$ \\
\hline 110 & 941208 & 125438 & 52.57 & 29.03 & 5.1 & 1 & 6.5 & 1R \\
\hline 111 & 940620 & 90902 & 52.5 & 29.2 & 6.1 & 9 & $18.5-98.85$ & $6 \mathrm{R}+3 \mathrm{SR}$ \\
\hline 112 & 941029 & 65207 & 55.88 & 27.62 & 5.0 & 1 & 24.5 & $1 \mathrm{HS}$ \\
\hline 113 & 941203 & 13551 & 49.12 & 37.37 & 5.0 & 1 & 32.5 & $1 \mathrm{HS}$ \\
\hline 114 & 941102 & 123101 & 49.41 & 36.81 & 5.0 & 1 & 28.5 & $1 \mathrm{HS}$ \\
\hline 115 & 941029 & 65207 & 55.88 & 27.62 & 3.9 & 1 & 41 & $1 \mathrm{HS}$ \\
\hline 116 & 950107 & 10919 & 51.93 & 29.28 & 4.8 & 1 & 31 & $1 S R$ \\
\hline 117 & 951009 & 85449 & 49.39 & 36.76 & 4.6 & 1 & 32 & $1 \mathrm{R}$ \\
\hline 118 & 951109 & 61024 & 59.58 & 36.28 & 4.6 & 1 & 73 & $1 S R$ \\
\hline 119 & 950322 & 62836 & - & - & 4.8 & 1 & 37 & $1 \mathrm{SR}$ \\
\hline 120 & 951015 & 65641 & 49.36 & 37.19 & 5.1 & 1 & 30.5 & $1 \mathrm{HS}$ \\
\hline 121 & 950726 & 124417 & 59.58 & 36.28 & 4.5 & 1 & 35 & $1 \mathrm{R}$ \\
\hline 122 & 951127 & 143144 & - & - & 5.1 & 1 & 16 & $1 \mathrm{HS}$ \\
\hline 123 & 950716 & 164223 & 52.85 & 29.09 & 5.0 & 1 & 30.5 & $1 \mathrm{R}$ \\
\hline 124 & 960124 & 60316 & 50.99 & 29.47 & 5.1 & 1 & 11.5 & 1SS \\
\hline 125 & 960124 & 60411 & 51.12 & 29.38 & 4.8 & 1 & 12 & $1 \mathrm{R}$ \\
\hline 126 & 960101 & 141952 & 50.99 & 29.47 & 3.8 & 1 & 17 & 1SS \\
\hline 127 & 960126 & 130958 & 51.12 & 29.38 & 5.0 & 1 & 10.5 & $1 \mathrm{R}$ \\
\hline 128 & 960316 & 201722 & 51.12 & 29.38 & 3.9 & 1 & 12 & $1 \mathrm{R}$ \\
\hline 129 & 970204 & 103747 & 57.29 & 37.66 & 6.4 & 4 & $19.9-246.5$ & $2 \mathrm{SR}+2 \mathrm{HS}$ \\
\hline
\end{tabular}




\begin{tabular}{|c|c|c|c|c|c|c|c|c|}
\hline 130 & 970228 & 125745 & 48.06 & 38.07 & 6.1 & 6 & 6.3-121.6 & $4 \mathrm{HS}+2 \mathrm{SS}$ \\
\hline 131 & 970510 & 75729 & 59.98 & 33.55 & 7.3 & 12 & $73.1-440$ & $2 \mathrm{R}+6 \mathrm{SR}+4 \mathrm{HS}$ \\
\hline 132 & 980314 & 194027 & 57.65 & 30.07 & 6.9 & 3 & $51.52-125$ & $1 \mathrm{SR}+2 \mathrm{HS}$ \\
\hline 133 & 990506 & 230053 & 52.11 & 26.46 & 6.1 & 12 & $20.5-129.5$ & $2 \mathrm{R}+3 \mathrm{SR}+6 \mathrm{HS}$ \\
\hline 134 & 991031 & 150939 & 51.81 & 29.41 & 5.2 & 3 & $16.9-80.6$ & 1SR+2HS \\
\hline 135 & 020622 & 25820 & 48.93 & 35.67 & 6.5 & 21 & 23-319 & $5 \mathrm{R}+8 \mathrm{SR}+8 \mathrm{HS}$ \\
\hline 136 & 031226 & 15656 & 58.35 & 29.09 & 6.5 & 13 & $3-279$ & $2 \mathrm{R}+2 \mathrm{SR}+8 \mathrm{HS}+1 \mathrm{SS}$ \\
\hline 137 & 040528 & 123846 & 51.81 & 36.52 & 6.3 & 46 & $3.95-473.7$ & $8 \mathrm{R}+13 \mathrm{SR}+24 \mathrm{HS}+1 \mathrm{SS}$ \\
\hline 138 & 051127 & 102223 & 55.89 & 26.78 & 6 & 4 & $57.5-120$ & 2SR+1HS+1SS \\
\hline 139 & 050222 & 22526 & 56.73 & 30.8 & 6.3 & 8 & $15.1-92.67$ & $1 \mathrm{R}+1 \mathrm{SR}+6 \mathrm{HS}$ \\
\hline 140 & 060331 & 11702 & 48.91 & 33.62 & 6.1 & 2 & $76.1-115.2$ & 1R+1SR \\
\hline 141 & 070618 & 142949 & 50.86 & 34.52 & 5.5 & 1 & 155.05 & $1 \mathrm{HS}$ \\
\hline
\end{tabular}

Note: R: Rock, SR: Soft rock, HS: Hard (or stiff) soil, SS: Soft soil

Table 3 Site classifications according to Iranian code of practice for seismic-resistant design of building

\begin{tabular}{cccc}
\hline Soil Condition & Shear Wave Velocity & $\begin{array}{c}\text { Site } \\
\text { categories }\end{array}$ & $\begin{array}{c}\text { Site parameter } \\
\text { used in this study }\end{array}$ \\
\hline Rock & Vs $>750 \mathrm{~m} / \mathrm{s}$ & I & 3 \\
Very dense soil and soft rock & $350<\mathrm{Vs}<750 \mathrm{~m} / \mathrm{s}$ & II & 2 \\
Stiff soil & $175<\mathrm{Vs}<350 \mathrm{~m} / \mathrm{s}$ & III & 1 \\
Soft soil & Vs $<175 \mathrm{~m} / \mathrm{s}$ & IV & 0 \\
\hline
\end{tabular}

Table 4 Regression parameters for the proposed model

\begin{tabular}{|c|c|c|c|c|c|c|c|c|c|c|}
\hline & $a_{0}$ & $a_{1}$ & $a_{2}$ & $a_{3}$ & $a_{4}$ & $b_{1}$ & $b_{2}$ & $\tau$ & $\sigma$ & $\sigma_{\text {total }}$ \\
\hline$D_{a 5-95}$ & $0.271 \pm 0.12$ & 0.07 & 0.236 & $0.16 \pm 0.01$ & $-0.021 \pm 0.011$ & 1.24 & 1.02 & 0.23 & 0.21 & 0.313 \\
\hline$D_{a 5-75}$ & $0.21 \pm 0.035$ & $\begin{array}{c}- \\
0.473\end{array}$ & 0.31 & $0.097 \pm 0.008$ & $-0.052 \pm 0.016$ & 0.2 & 1.2 & 0.3 & 0.316 & 0.438 \\
\hline
\end{tabular}

$\sigma_{\text {total }}=\sqrt{\sigma^{2}+\tau^{2}}$ 


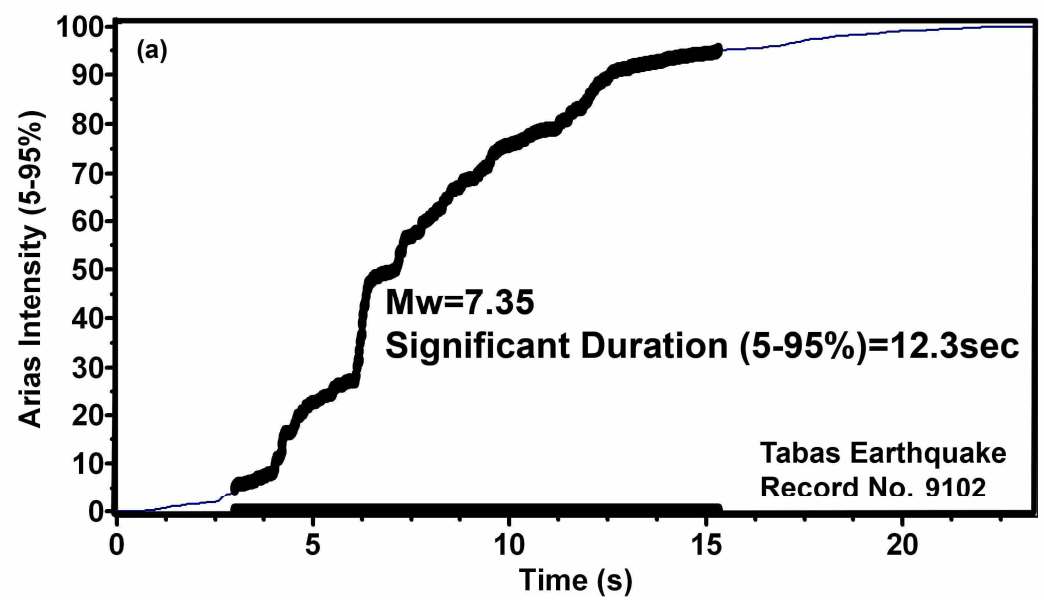

(a)

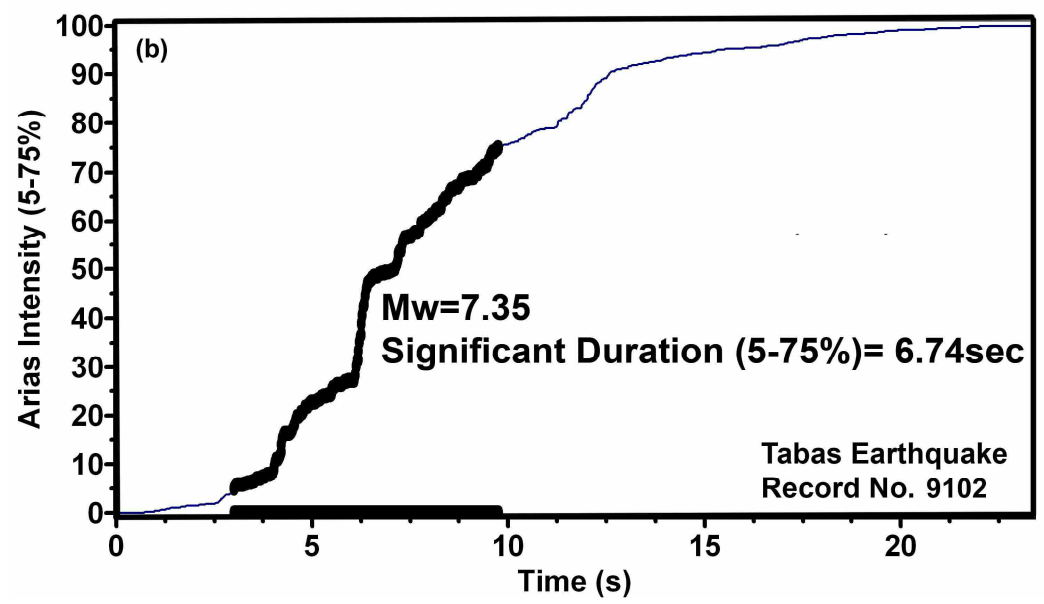

(b)

Fig. 1 Representation of significant duration for 1978 Tabas event, Deyhook station (a) $D_{a 5-95 \%}$ (b) $D_{a 5-75 \%}$ 


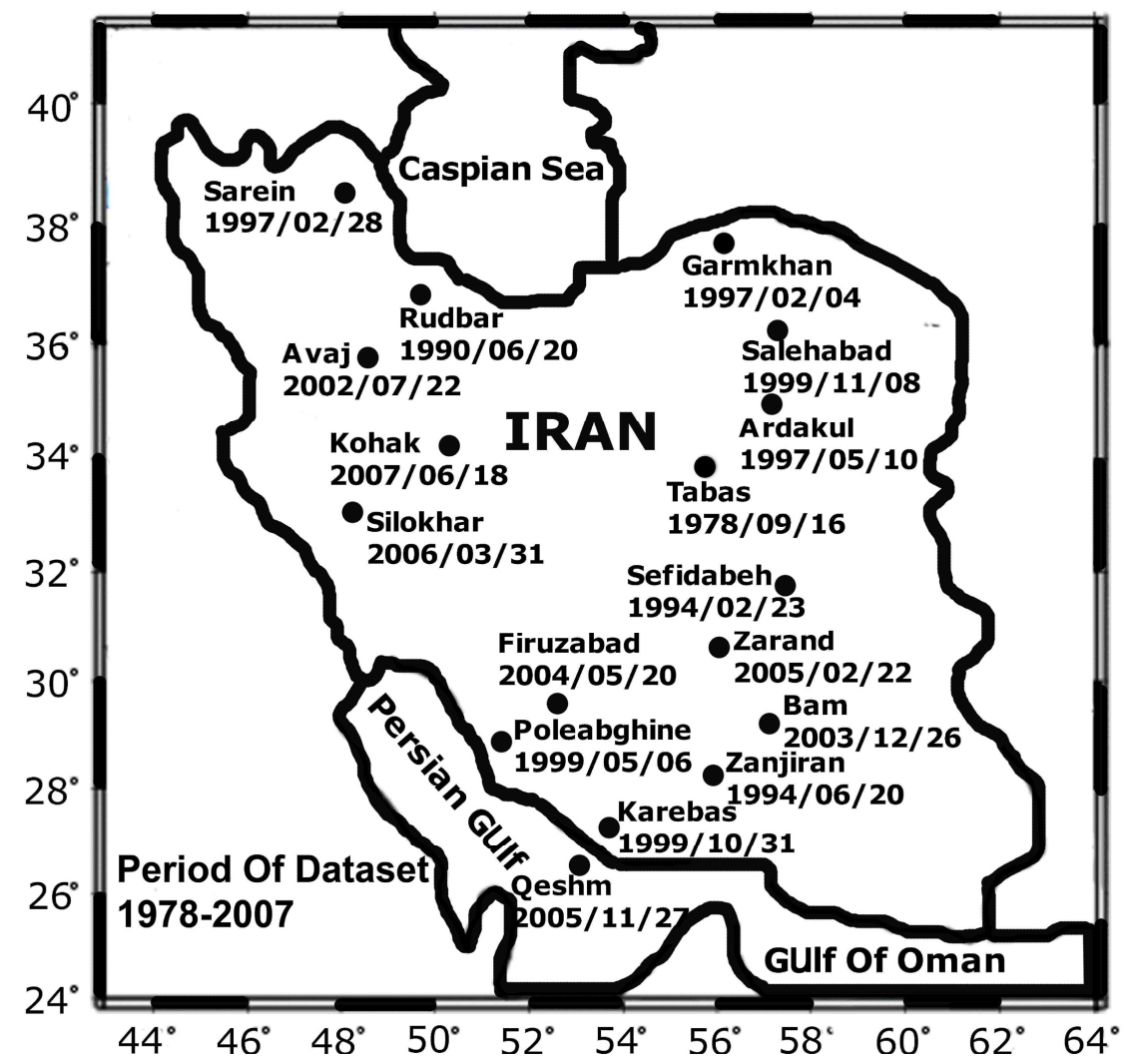

Fig. 2 Location of major earthquakes used in this study

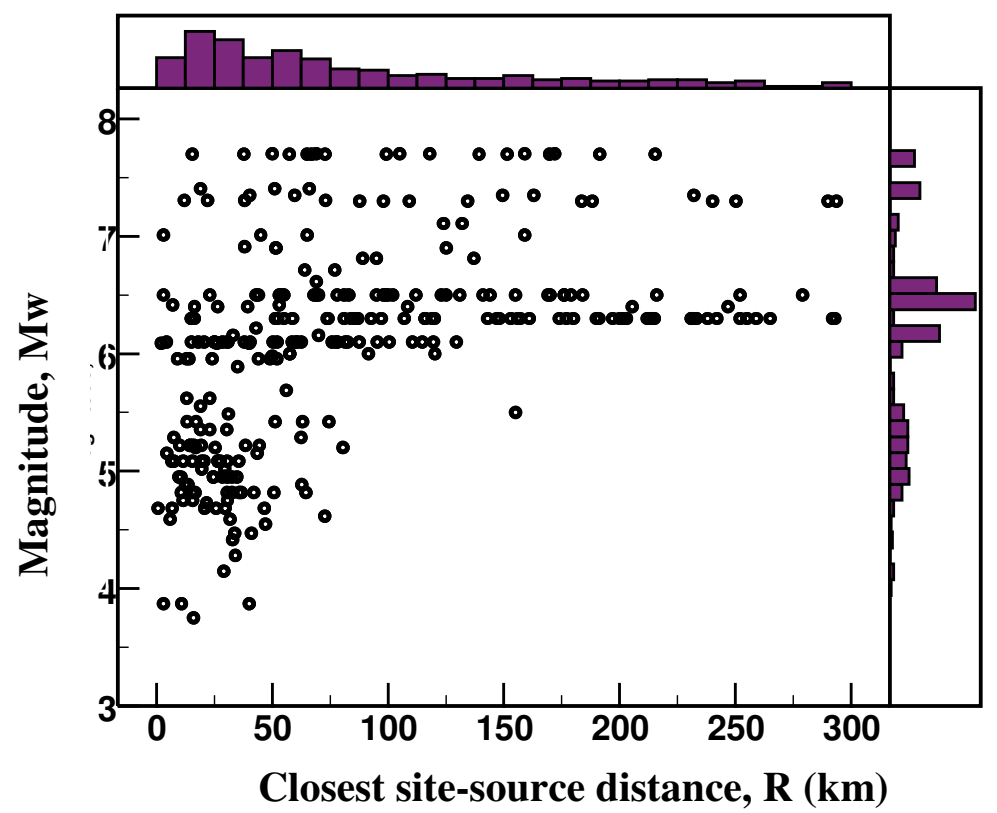

Fig. 3 Distribution of the selected dataset in terms of magnitude and closest site-source distance 


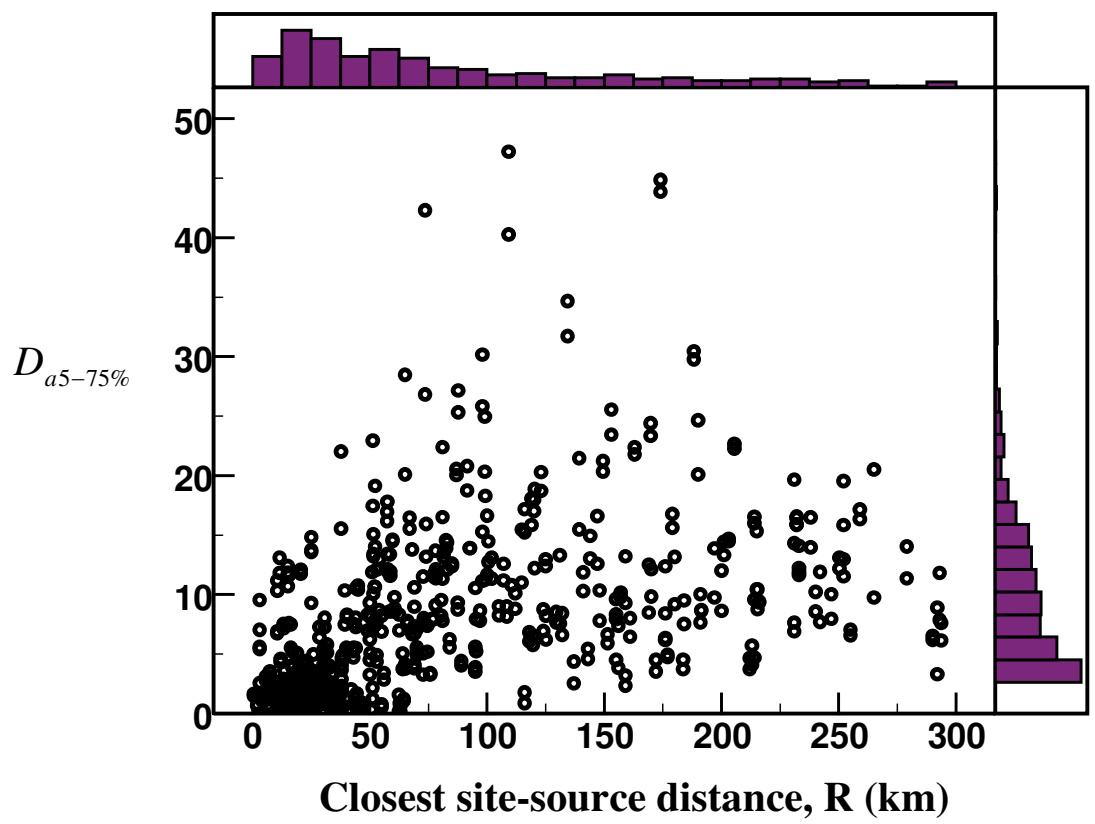

Fig. 4 Scatter plot of $D_{a 5-75 \%}$ vs. closest site-source distance for the dataset used in this paper

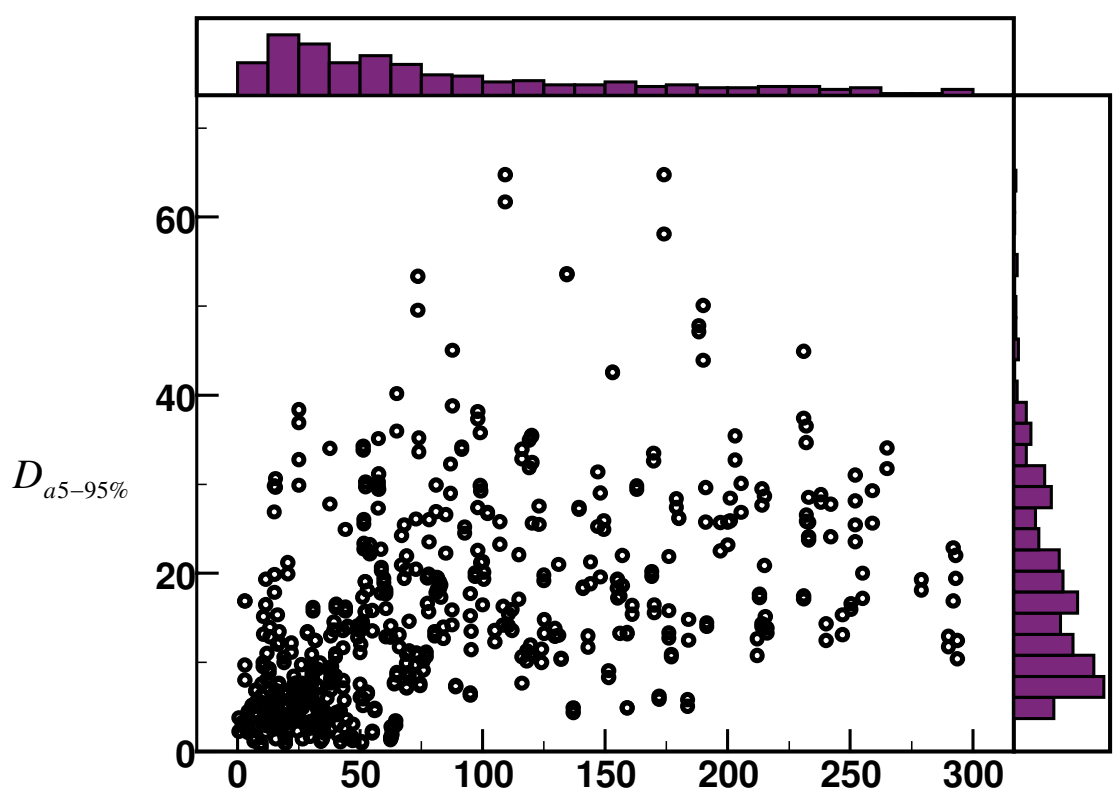

Closest site-source distance, $\mathbf{R}(\mathbf{k m})$

Fig. 5 Scatter plot of $D_{a 5-95 \%}$ vs. closest site-source distance for the dataset used in this paper 


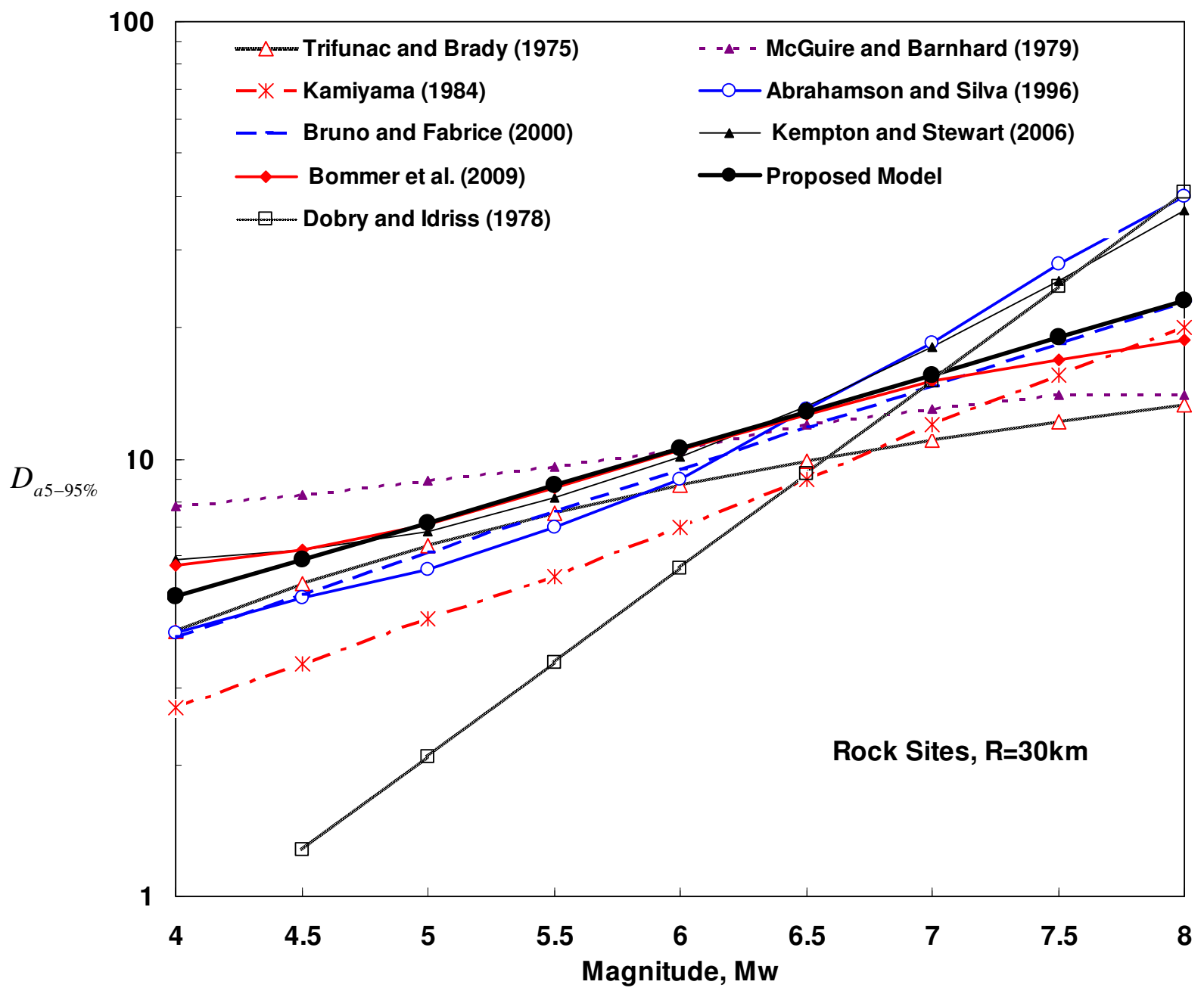

Fig. 6 Comparison of proposed model with other models for a fixed distance of $R=30 \mathrm{~km}$ on rock sites 


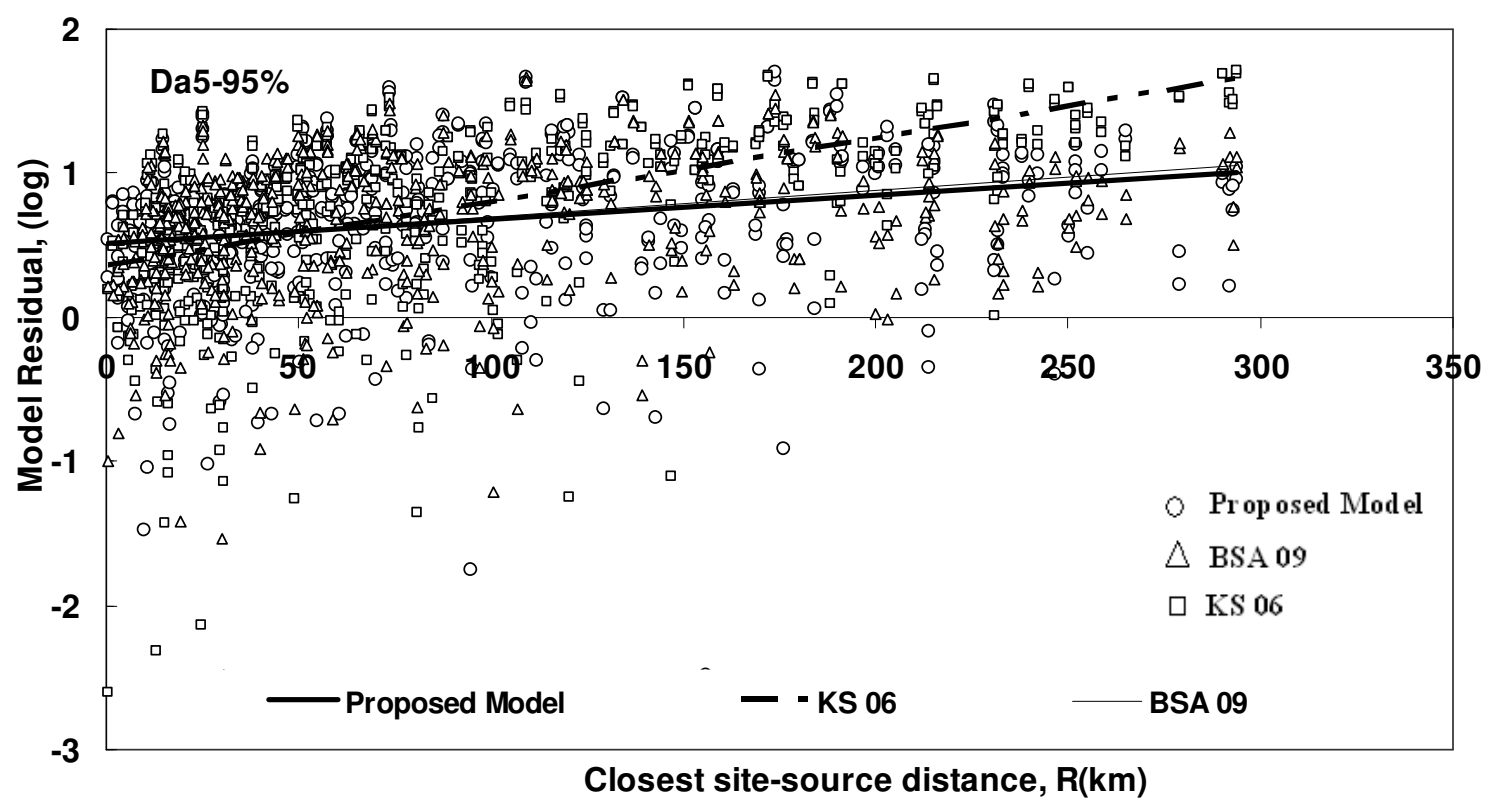

(a)

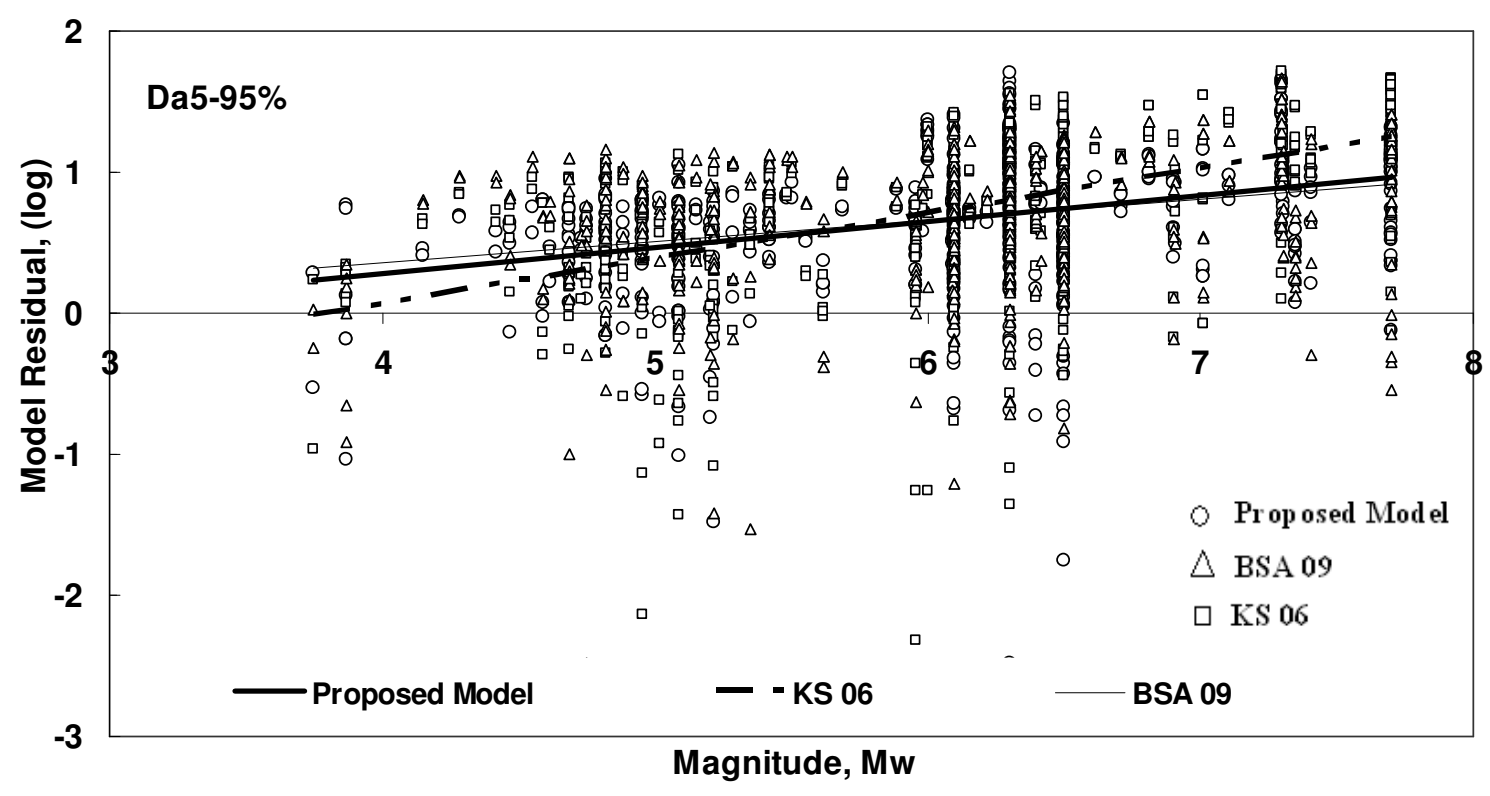

(b)

Fig. 7 The distribution of residuals between the observed and predicted significant duration $\left(D_{a 5-95 \%}\right.$ ) for the proposed model along with KSO6 (Kempton and Stewart, 2006) and BSA09 (Bommer et al., 2009) models with respect to (a) closest site-source distance and (b) magnitude. 


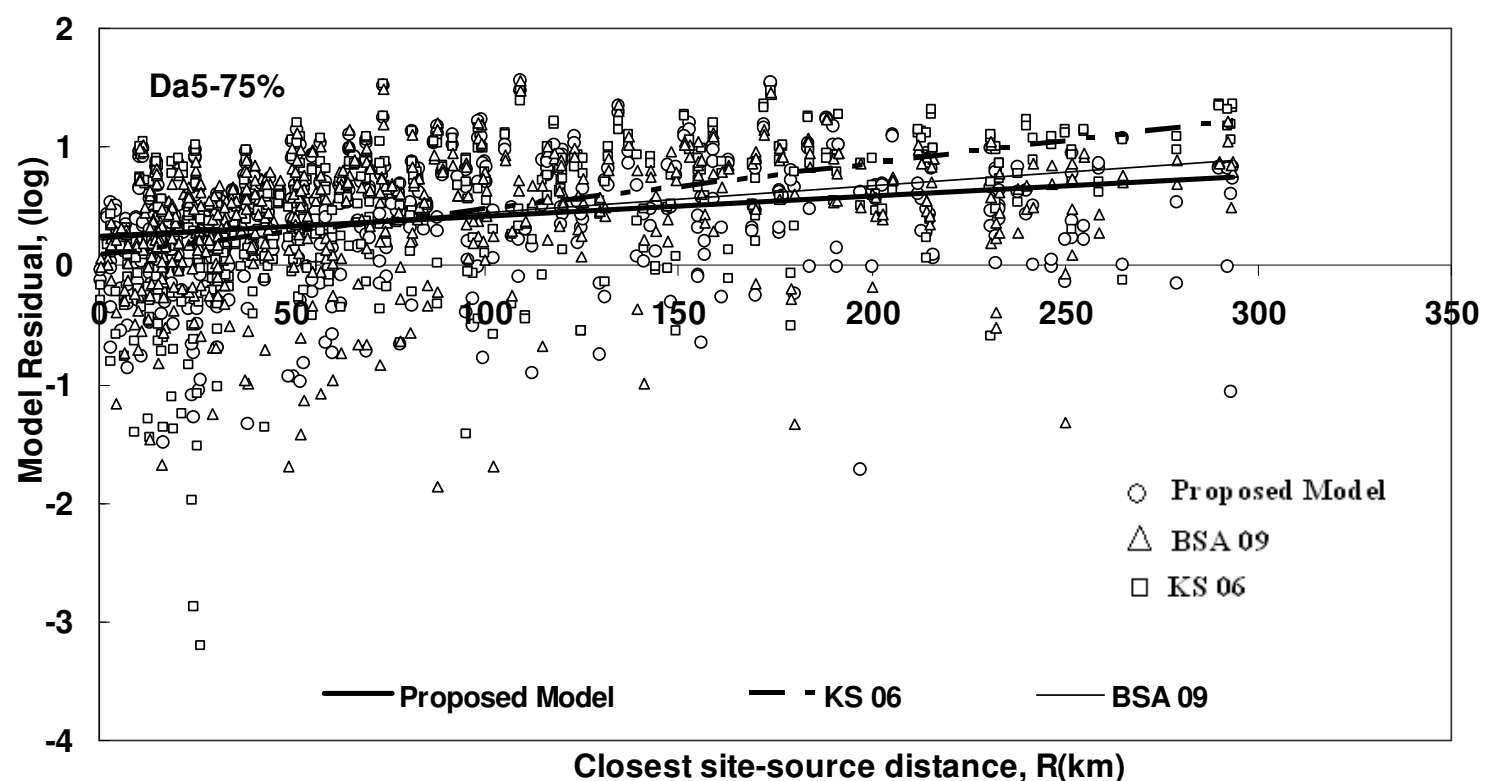

a)

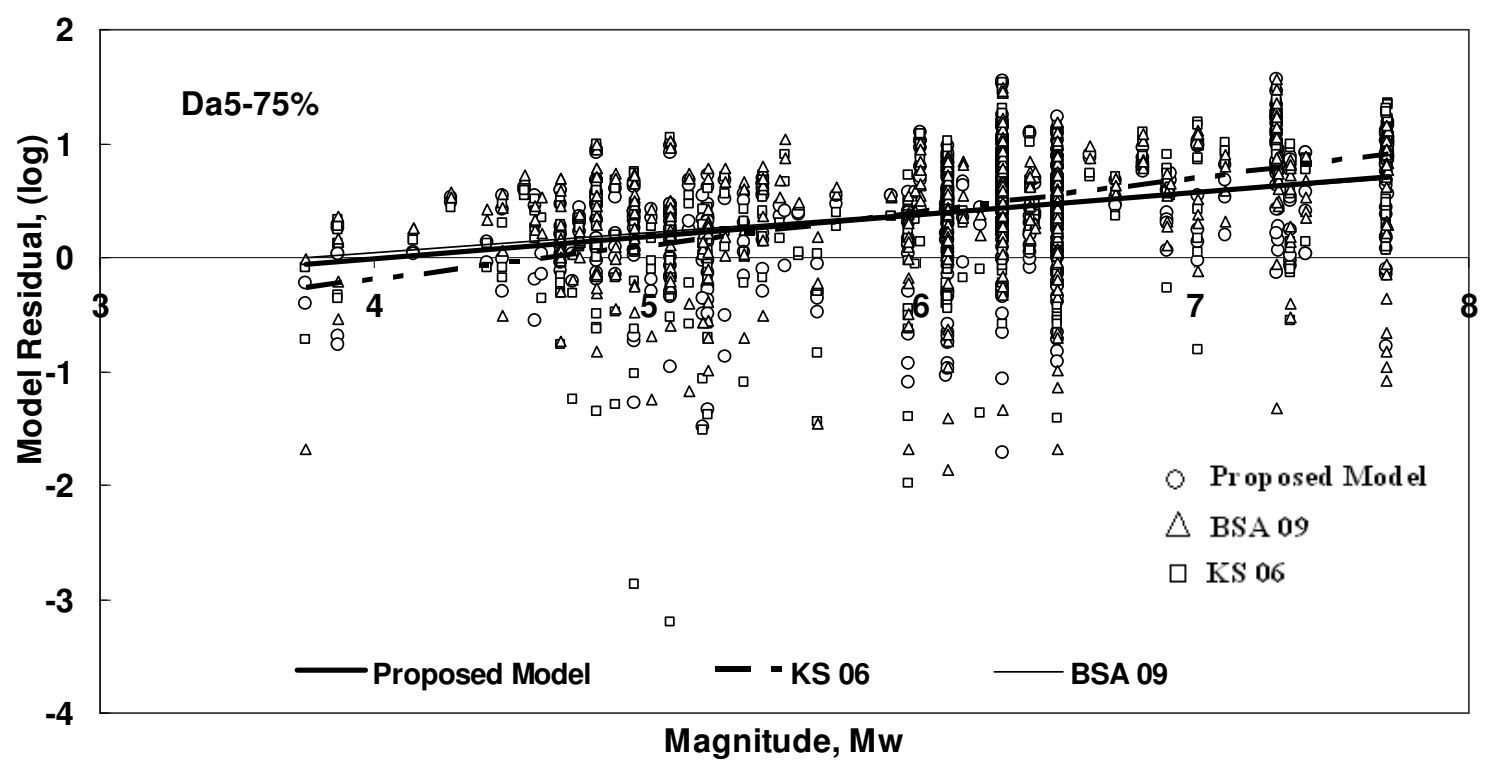

b)

Fig. 8 The distribution of residuals between the observed and predicted significant duration $\left(D_{a 5-75 \%}\right.$ ) for the proposed model along with KSO6 (Kempton and Stewart, 2006) and BSA09 (Bommer et al., 2009) models with respect to a) closest site-source distance and b) magnitude. 


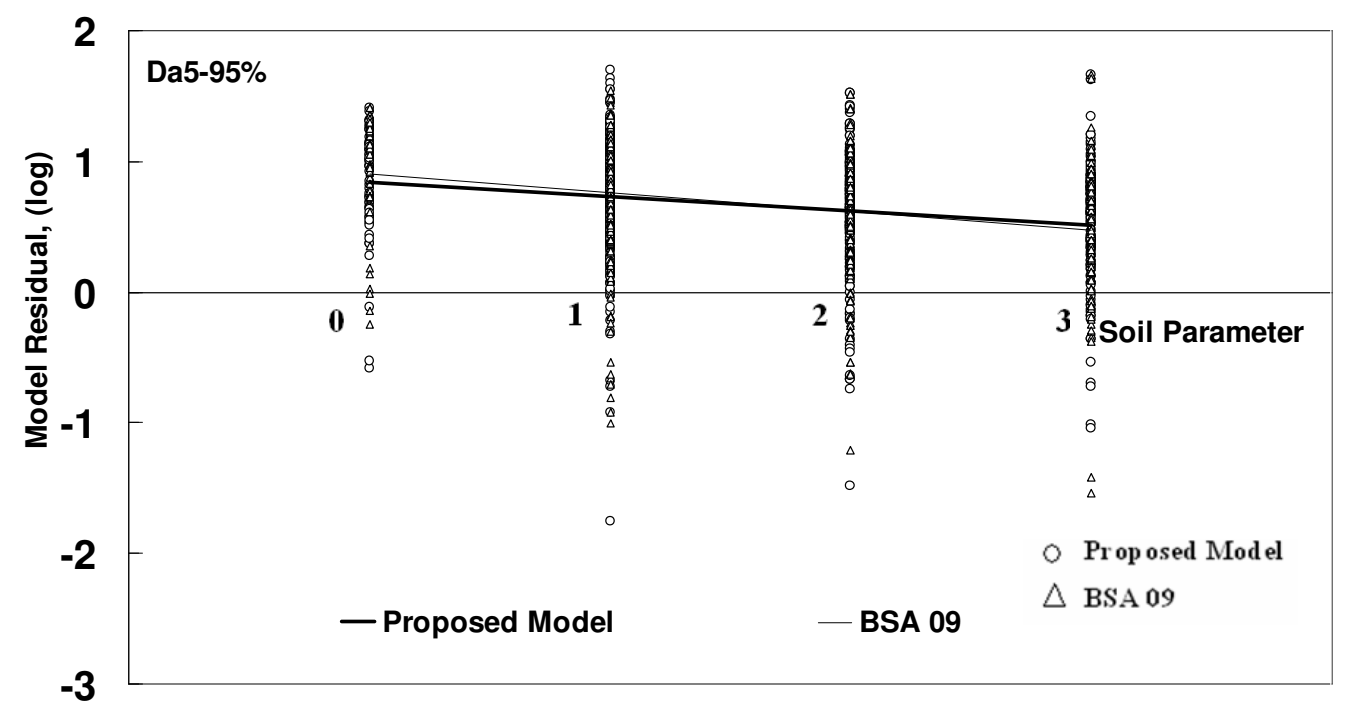

a)

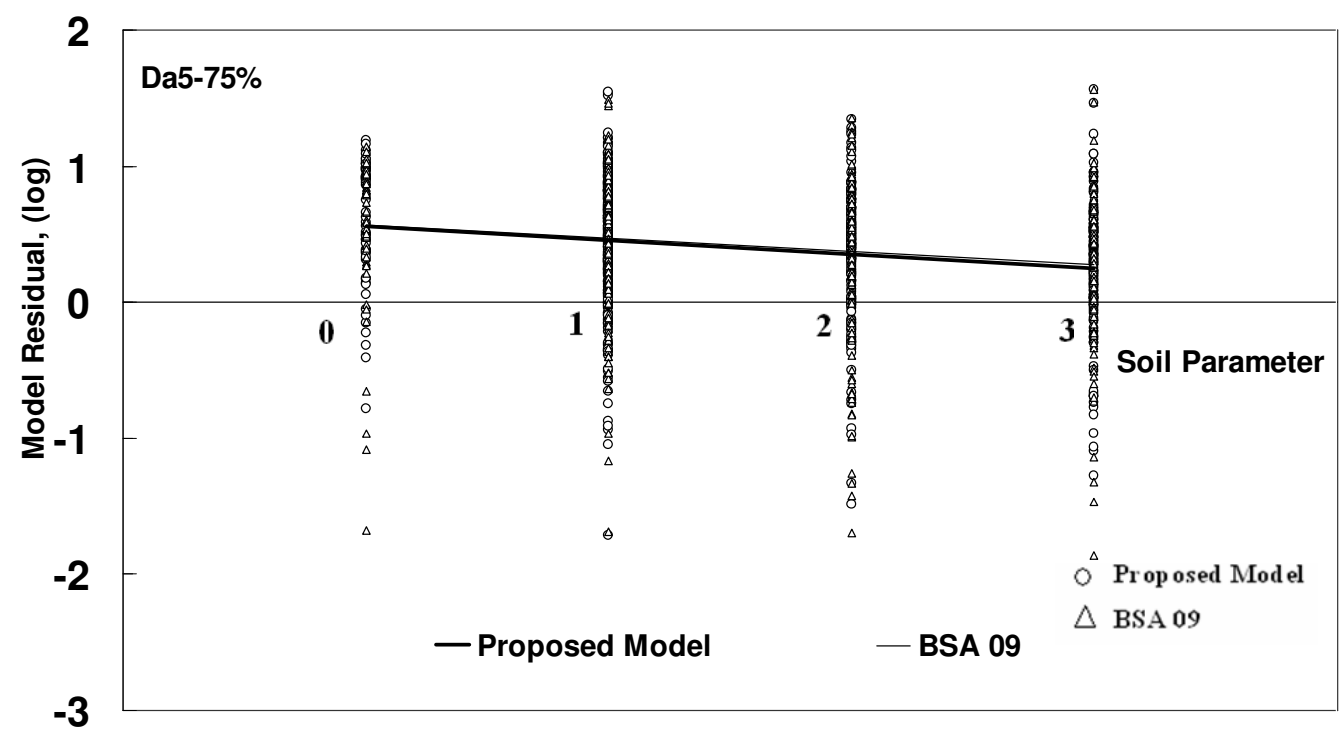

b)

Fig. 9 The distribution of residuals between the observed and predicted significant duration a) $D_{a 5-95 \%}$ b) $D_{a 5-75 \%}$ for the proposed model along with BSA09 (Bommer et al., 2009) model with respect to soil parameter $S=3,2,1$ and 0 , representing rock sites (site class B), very dense soil and soft rock (site class C), stiff soil (site class D) and soft soil (site class E), respectively. 


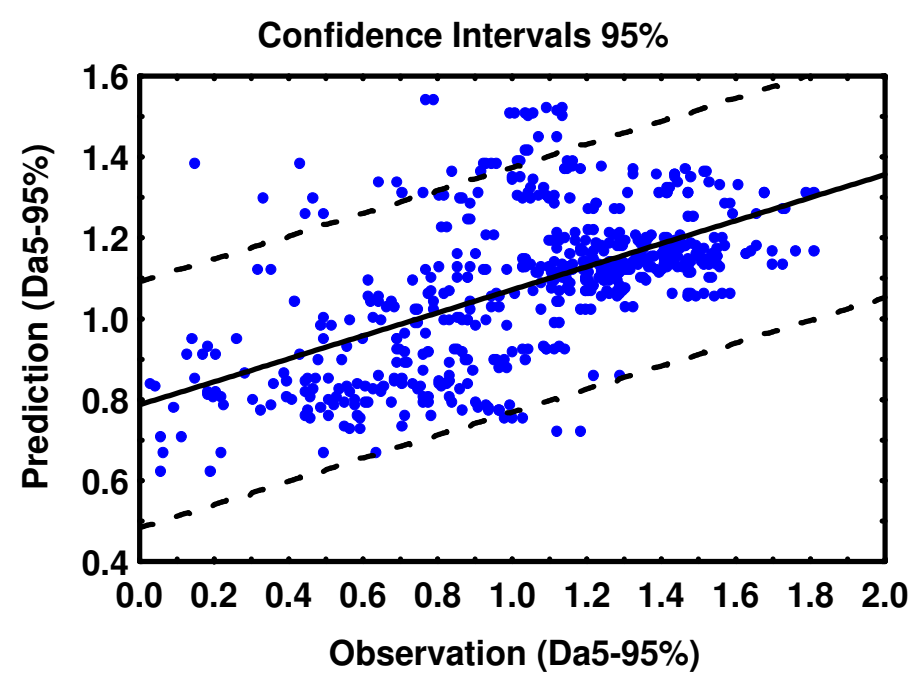

a)

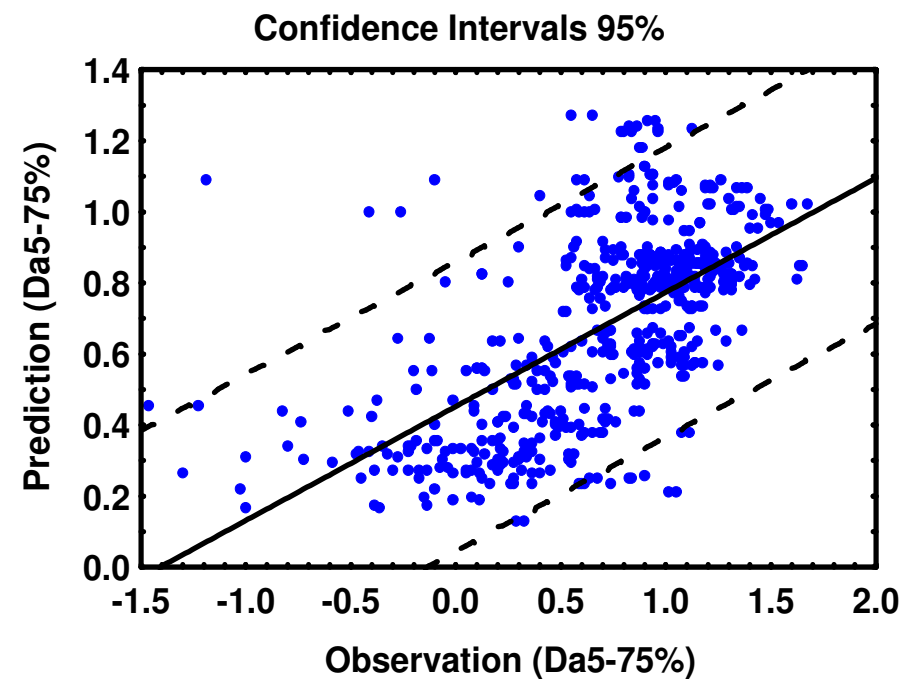

b)

Fig.10 Predicted versus observed significant duration of earthquake ground motion based on the model developed in this study: (a) $D_{a 5-95 \%}$ (b) $D_{a 5-75 \%}$ 